DOI: https://doi.org/10.24867/13AM03Kerepesi

\title{
AUTOMATIZOVANO PROGRAMIRANJE NUMERIČKI UPRAVLJANIH MAŠINA ALATKI ZA OBRADU GLODANJEM SA 4 I 5
}

\section{AUTOMATED PROGRAMMING OF NUMERICALLY CONTROLLED MACHINES FOR MILLING TOOLS WITH 4 AND 5 AXIS}

\author{
Mate Kerepeši, Slobodan Tabaković, Fakultet tehničkih nauka, Novi Sad
}

\begin{abstract}
Oblast - MAŠINSTVO
Kratak sadržaj - U radu se opisuju postupci 5-osne obrade glodanjem primenom numerički upravljanih mašina alatki i njihov značaj (uloga) u savremenim proizvodnim tehnologijama. Ovoj tehnologiji pomažu, softverska rě̌enja i inovativni rezni alati koji podržavaju simultanu 5 osnu obradu. Obrada, kao i prethodni procesi izrade su definisani uz pomoć softverskog paketa SolidWorks-a i sa integrisanim softverom SolidCAM-a koji služi za pripremu programa obrade. Kao primer je u radu prikazana 5 osna obrada elemenata pokretnog dela turbinskog kola, koji se sastoji od kompleksnih površina.
\end{abstract}

Ključne reči: Automatizovano programiranje NUMA, 5 osna obrada

Abstract - In this paper, the sequences of 5-axis CNC machining and his significance in today's production technologies are presented in detail. Helping this technology, software solution and innovative cutting tools are being showcased to support the 5-axis machining. The machining and the previous production processes were determined in the SolidWorks software package and the SolidCAM machining preparation program integrated into the package whose purpose is to prepare the processing program. The simultaneous 5-axis machining of a moving component of a turbocharger, consisting of complex surfaces, is demonstrated on the so-called compressor wheel (IMPELLER).

Keywords: Automated programming of CNC machines, 5 axis machining

\section{UVOD}

Obrada materijala skidanjem strugotine je jedan od najvažnijih proizvodnih procesa. Ova grupa postupaka obrade na svetskom tržistu učestvuje sa oko $70 \%$ od ukupnih proizvodnih procesa. Pošto je mašinska industrija sa aspekta ekonomije vrlo značajna i na evropskom i na svetskom nivou, taj procenat dosta govori o važnosti procesa obrade skidanjem strugotine. Nove generacije industrijskih postrojenja su osposobljene da snimaju i integrišu različite informacije u proizvodni sistem.

Savremeno tržište zahteva visoko kvalitetne proizvode, proizvedene za što kraće vreme i što je moguće jeftinije. Zbog toga kompanije moraju biti spremne da ispune ove zahteve tržišta da bi bile konkurentne i uspešne.

\section{NAPOMENA:}

Ovaj rad proistekao je iz master rada čiji mentor je bio dr Slobodan Tabaković, red. prof.
Da bi ovo postigla, savremena industrija se bazira na skraćenju vremena projektovanja i proizvodnje. U oblasti tehnologije obrade skidenjem strugotine akcenat je na skraćenju pomoćnih i glavnih vremena, kao i na uštedama proizvodnih sredstava (alata, pribora, SHP-sredstava).

U radu se opisuje kategorizacija postupaka petoosne obrade i primenom softvera SolidWorks i SolidCAM integracionog modula na jednom konkretnom primeru prikazuje kompletan razvoj upravljačkog programa. $\mathrm{Na}$ primeru konkretnog proizvoda se prikazuje mogućnost petoosnih mašina za obradu glodanjem uz pomoć savremenog softvera i savremenih reznih alata.

\section{OPERACIJE POZICIONE VIŠEOSNE OBRADE}

Geometrijski gledano pomoću petoosnih numerički upravljanih mašina alatki moguće je u jednom stezanju obraditi pet od šest strana prizmatičnog komada. Do jedne strane se može doći iz vertikalnog položaja, a ostale četiri iz horizontalnog položaja glavnog vretena, to zahteva i rotaciju stola, tj. repozicioniranje radnog predmeta. Taj proces započinje definisanjem se nominalni koordinatni sistem koji određuje položaj pripremka u radnom prostoru, a sve rotacije radnog predmeta se definišu u odnosu na njega. U upravljački program se unosi promena ose alata (vertikalno/ horizontalno)

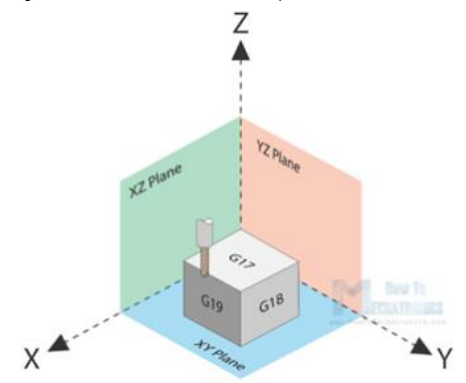

2.1. Slika Vertikalni položaj vretena

programiranjem odgovarajuće trenutno aktivne ravni obrade primenom G17/G18/G19 komande. U vertikalnom položaju vretena, kada se programira $\mathrm{G} 17$, osa alata postaje „Z“', a ravan $\mathrm{X} / \mathrm{Y}$ je glavna ravan interpolacije. $\mathrm{S}$ druge strane, u horizontalnom položaju vretena, prilikom programiranja G18, osa alata postaje Y, dok je glavna ravan interpolacije definisana Z/X osama. Kompletna obrada pet upravnih strana obradka može se na taj način odvijati u jednoj mašini. Na taj način se smanjuje vreme obrade, a kvalitet $\mathrm{i}$ tačnost obrađenog radnog predmeta povećavaju zbog manjeg broja stezanja. Procenjuje se da ovaj tip obrade čini $30 \%$ svake petoosne obrade. Ovaj vid programiranja petoosne obrade je pogodan i za ručno i automatizovano programiranje. 


\subsection{Obrada 3+2 osa}

Petoosna $(3+2)$ obrada se može posmatrati kao konvencionalna troosna obrada sa rotiranjem stola oko odgovarajuće ose (,A“ osa predstavlja rotaciju oko $\mathrm{X}$ ose mašine, „B“ oko Y ose a „C"rotacija oko Z ose) Da bi se izvršilo rotiranje (pozicioniranje) obradka u položaj za obradu, potrebno je izvršiti transformaciju koordinatnog sistema tako da je osa alata uvek Z osa, a obrada se odvija u X/Y ravni. Programiranje u rotiranoj ravni može se izvršiti sa G17 na način koji je već dobro poznat po obradi sa 2.5 ose. Ova vrsta obrade predstavlja kombinaciju obrade sa 5 stranica, kose ravni, obrade rupa i otvora. Procenjuje se da ovaj tip obrade čini $60 \%$ petosne obrade. CAM softver je neophodan kod programiranja složenijih zadataka.

\subsubsection{Mogućnosti transformacije koordinatnog sistema}

Upravljačke jedinice koje se koriste za upravljanje mašinama alatkama sa pet numerički upravljanih osa poseduju više načina za postavljanje koordinatnog sistema-a:

- Slobodno definisana ravan (PLANE SPATIAL)

- Projektovana ravan (PROJECTED PLANE)

- Ravan definisana u skladu sa Ojlerovim koordinatama (EULER PLANE)

- Vektorski definisana ravan (VECTOR PLANE)

- Definisanje ravni sa tri tačke (POINTS PLANE)

- Definisanje u odnosu na ravan (PLANE RELATIVE)

Zajednička karakteristika ovih ciklusa pozicioniranja je to što omogućavaju transformaciju nepokretnog (statičnog) koordinatnog sistema. To znači da upravljačka jedinica, uz pomoć osa rotacije dostupnih na mašini, tako pozicionira radni predmet da je osa alata „Z" normalna na površinu koja se obrađuje. Posle ovoga se položaj koordinatnog sistema više neće menjati tokom obrade (ostaje fiksan). Ciklusi transformacije, tokom izvršenja, „,nose sa sobom” podatke o nultoj tački i korekciji alata. $\mathrm{Na}$ ovaj način možemo obrađivati svih 5 stranica prizmatičnog dela sa jednom nultom tačkom. Upravljačka jedinica vrši konverziju uzimajući u obzir kinematski lanac mašine alatke. Tokom obrade, osa alata je uvek osa „Z”. Gore navedeni ciklusi nagiba koordinatnog sistema omogućavaju nezavisno kretanje u odnosu na mašinu alatku, odnosno upravljačka jedinica konvertuje uglove rotacije $\mathrm{u}$ odnosu na trenutni položaj koordinatnog sistema mašine. U nastavku se prikaže tri najčešće korišćene transformacije koordinatnog sistema.

\subsubsection{Slobodno definisana ravan (PLANE SPATIAL):}

Slobodno definisanje ravni obrade primenom prostornih uglova predstavlja najčešće korišćeni metod definisanja položaja radnog predmeta u odnosu na osu alata. To ujedno predstavlja najčešće korišćeni ciklus pripreme pozicione petoosne obrade. Zajedno sa PLANE RELATIVE ciklusom, koristi se u oko $90 \%$ slučajeva. Ravan obrade se može definisati u fiksnom koordinatnom sistemu mašine (redosled rotacije: $A>B>C$ ) ili $u$ nagnutom koordinatnom sistemu obratka (redosled rotacije: $\mathrm{C}>\mathrm{B}>\mathrm{A}$ ) unošenjem 3 prostorna ugla (rotacije oko glavnih osa). Sa praktične tačke gledišta, treba koristiti redosled rotacije $\mathrm{C}>\mathrm{B}>\mathrm{A}$, pri čemu se nagnuti koordinatni sistem obratka uzima uvek $\mathrm{u}$ datom redosledu. Cilj je da osa alata „Z" nakon rotacije bude usmerena od ravni ka spolja, prema glavnom vretenu. Smer druge dve ose je zanimljiv sem ako se isti redosled pokreta mora izvršiti tokom različitih rotacija ravni. Drugim rečima, ako su ose "X/Y" iste nakon svakog nagiba ravni, lakše je prilagoditi program ili korišćenjem potprograma smanjiti vreme programiranja.

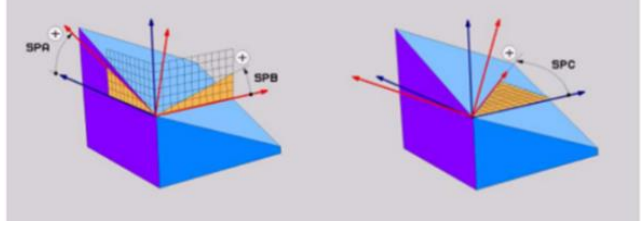

2.2. Slika Prostorni uglovi SPA, SPB i SPC

Tri prostorna ugla SPA, SPB i SPC moraju biti navedena čak $\mathrm{i}$ ako je njihova vrednost 0 . Za pojedinačnu rotaciju po osi se koristi ciklus PLANE RELATIVE. Gore pomenuti redosled rotacije je nezavisan od aktivne ose alata.

2.1.1.2 Projektovana ravan (PLANE PROJECTED):

Ravni obrade se primenom projektovane ravni definišu sa uglovima projekcije. Obrada se može definisati u fiksnom koordinatnom sistemu mašine sa dva ugla projekcije, od kojih se prvi projektuje na nagnutu „XZ” (PROPR) ravan, drugi na „YZ” (PROMIN) ravan (Gde je osa alata Z osa), a zatim rotira oko nagnute ose alata ,Z” (ROT) može biti određen sa uglom koji zaklapa sa „X” osom.

Ovde je takođe cilj da osa ,Z” bude okrenuta prema spolja.

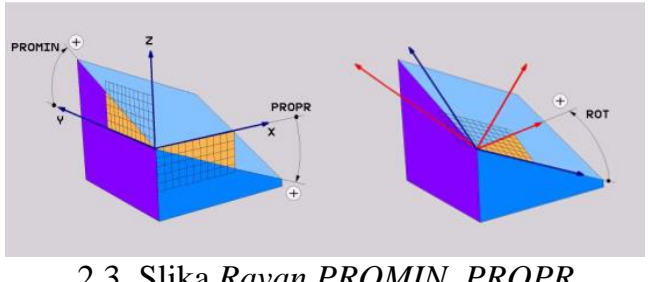

2.3. Slika Ravan PROMIN, PROPR

Pri obradi rupa i otvora pod uglom, preporučuje se upotreba kosog položaja, tamo gde su rupe prikazane samo u kosoj projekciji na crtežu (ne u presečnoj ravni). Za ravansku obradu uglovi za projekciju mogu se koristiti samo ako se obrađuje pravougaoni stub (komad), u suprotnom će radni predmet biti izobličen.

\subsubsection{Ravan definisana u skladu sa Ojlerovim koordinatama (PLANE EULER):}

Određivanje ravni obrade Ojlerovim uglovima. Sa EULER uglovima, ravan obrade se uvek može odrediti pojedinačno, sa najviše tri rotacije oko ose prethodno rotiranog koordinatnog sistema.

Prva rotacija se vrši oko „Z” ose (EULPR), zatim se rotira oko „X” ose (EULNU) i na kraju rotacija oko „Z" ose (EULROT). Osa alata „Z” treba da bude okrenuta prema spolja u odnosu na ravan obrade.

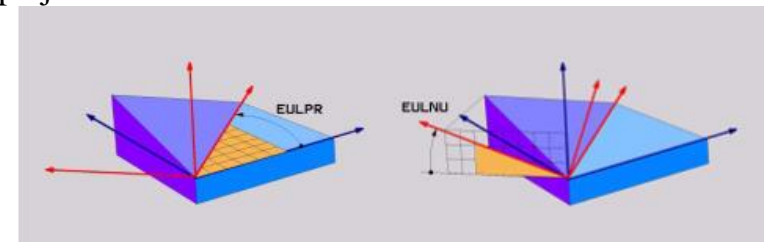

2.4. Slika. Ojlerovi uglovi EULPR i EULNU

Opseg definicije za svaki EULER ugao je vrlo ograničen, pa to nije jedna od najpopularnijih komandi za transformaciju KS-a. 


\subsubsection{Vektorski definisana ravan (VECTOR PLANE):}

Određivanje ravni obrade pomoću dva vektora. Definisanje ravni obrade sa dva vektora se može koristiti ako CAM sistem može izračunati osnovni i normalni vektor kod nagnute ravni. Nije potrebno pretvaranje vektora $u$ jedinične vektore, jer to čini upravljački sistem, tako da raspon ulaznih vrednosti vektora može biti u opsegu $-99,9999999$ $\div$ 99,9999999. Osnovni vektor potreban za određivanje ravni obrade može se odrediti komponentama BX, BY i BZ, dok se normalni vektor može odrediti komponentama NX, NY i NZ. Osnovni vektor B definiše pravac X ose u rotiranoj obradnoj ravni, dok normalni vektor $\mathrm{N}$ definiše pravac obradne ravni i normalan je na nju.

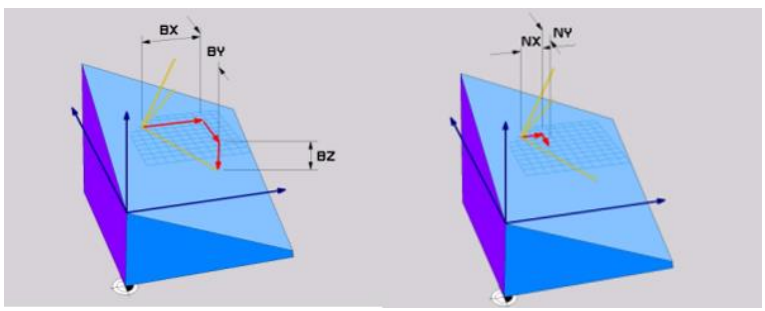

2.5. Slika. Normalni vektori $N X, N Y, N Z$

Primer definisanja jediničnog vektora: Na gornjoj slici koordinatni sistem označen crvenom bojom je osnova, dok je nagnuti koordinatni sistem prikazan žutom bojom. Pravac $\mathrm{X}$ ose je podrazumevan $\mathrm{BX}=1 \quad \mathrm{BY}=0 \quad \mathrm{BZ}=0$. Budući da se komponente normalnog vektora nagnute ravni u većini slučajeva ne mogu pročitati direktno sa radioničkog crteža, njihova definicija zahteva određeni prostorni vid i matematičko znanje, pa ih primenjujemo samo u posebnim slučajevima.

\section{Simultana petoosna obrada:}

Simultana petoosna obrada obuhvata zahvate obrade kod kojih se kretanje alata u okviru jedne programske rečenice definiše sa parametrima koji određuju poziciju alata $u$ svih 5 numerički upravljanih osa. Ovaj tip obrade zahteva neprekidnu transformaciju koordinatnog sistema koja se može postići upotrebom funkcije TCPM (Tool Center Point Managment - Upravljanje tačkom centra alata), koja se koristi za automaatizovanu promenu korekcije putanje na osnovu promene pozicije vrha alata. Procenjuje se da ovaj tip obrade čini oko $10 \%$ petosne obrade. Najčešće se programira uz pomoć CAM softvera.

\subsection{TCPM funkcija}

Rešenje se pokazalo pojavom funkcije TCPM (Slika 3.1 ), gde se pored interpolacionih komanda, posmak takođe odnosi na vrh alata, tako da se tokom obrade, pozicija alata relativno $\mathrm{u}$ odnosu na radni komad ne menja tokom kretanja. Na ovim mašinama, koordinatni sistem obratka ostaje konstantan (nema naginjanja stola), pa se putanja alata može odrediti relativno lakim matematičkim proračunima. U današnje vreme je nezamislivo koristiti sinhronizovanu petoosnu obradu bez ove funkcije. Ona se može takođe koristiti za inkrementalno programiranje naginjanja kako bismo postigli bolje uslove obrade.

\subsubsection{Mogućnosti programiranja TCPM funkcijom} M128 (Slika 3.1): Predstavlja najčešće korišćenu formu TCPM funkcije. U suštini, potrebno je znati da ne generiše 3D rotaciju. Preporučuje se da se programira sa alatom koji ima loptasti vrh (ball-endcutter), jer druge vrste alata mogu prouzrokovati podrezivanje (undercut) tokom rotacije. Pomoću parametara mašine možemo odrediti na šta se odnosi pomak.

4 Specijalni rezni alati za simultanu petosnu obradu Usavršavanjem kinematike i upravljačkih sistema, kretanja alata kod mašina alatki su postajala sve zamršenija (složenija). Tokom tog perioda, oblici reznih alata su ostali jednostavni. Standardna glodala dolaze u osnovnim oblicima koji su bili dobro prepoznatljivi i pre pojave CNC mašina. Savremene mašine mogu obrađivati specijalne forme (oblike) korišćenjem profilisanih alata obezbeđujući bolje rezultate procesa skidanja materijala.

Alati sa torusnim segmentom se izrađuju u 4 različita oblika geometrije (Slika 4.1):

- konusni oblik (taper form)

- ovalni oblik (oval form)

- oblik sočiva (lens shape)

- buričasti oblik (barrel-shaped)

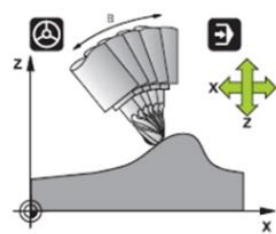

\subsection{Slika Funkcija} M128

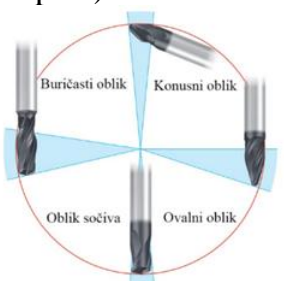

4.1. Slika Alati sa torusno segmentom

\section{Izrada turbine na Hermle C42U MT Dynamic CNC mašini alatki}

Cilj ovog rada jesteizrada konkretnog radnog predmeta primenom programskog sistema SolidCAM. Verifikacija putanje alata biće urađena u već definisanoj mašinskoj simulaciji SolidCAM-a, a G-kod je generisan sa već definisanim postprocesorom za Hermle C42U mašinu alatku. Za radni predmet je izabrana modifikovana turbina sa logoima firmi koji su obezbedili podršku da bi se mogao realizovati ovaj rad, Fakulteta Tehničkih Nauka i Departmana za prozvodno mašinstvo, čija projekcija na zakrivljenu površinu daje gravuru. Logo Fakulteta i Departmana je malo modifikovan u odnosu na original iz praktičnih razloga.

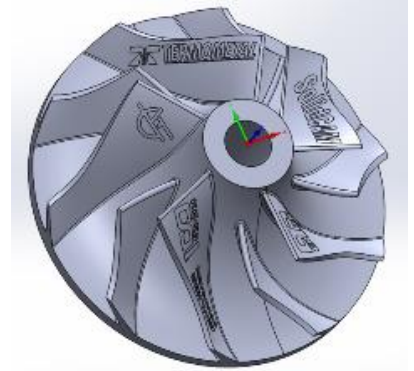

\subsection{Slika 3D model stvarnog dela}

\subsection{Obradni centar korišćen za izradu lopatice turbine}

Mašina na kojoj je realizovana obrada lopatice turbine je petosni obradni centar prozvođača Hermle generacija C42U MT Dynamic. Mašina C42U MT Dynamic ima mogućnost i realizacije zahvata struganja rotacijom oko C-ose sa brojem obrtaja $8001 / \mathrm{min}$. Upravljačka jedinica na mašini je Heidenhain TNC 640.

\subsection{Simulacija obrade i verifikacija putanje alata}

Projektovani tehnološki postupci obrade radnog predmeta i generisana putanja alata se mogu verifikovati, primenom simulacije u programskom sistemu SolidCAM. 


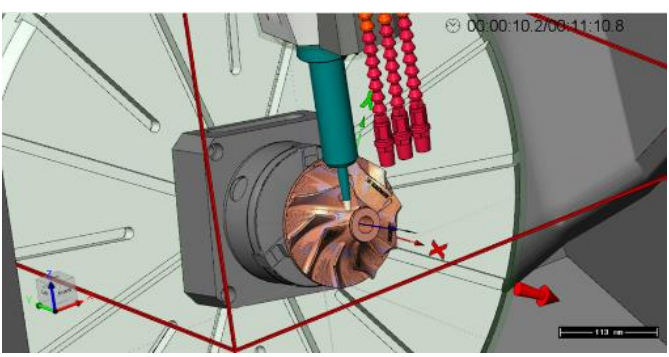

5.2. Slika. Mašinska simulacija

\subsection{Rezultat merenja na koordinatnoj mernoj mašini}

Treba naglasiti da ovaj konkretan komad za izradu nije rađen na osnovu zahteva kupaca, već da se u praktičnom primeru prikaže primer petosne obrade, poteškoće i moguća rešenja. Uz pomoć koordinatne merne mašine skeniranjem obrađenih površina dobijen je oblak tačaka urađenog komada, pa je upoređeno sa 3D modelom, tolerancija je podešena na $\pm 0.5 \mathrm{~mm}$.

U tabeli 5.1. može se videti da svaka merena tačka sa urađenog komada je u opsegu podešene tolerancije. Gotov izradak prikazan na slici 5.3, lopatica turbine sa logoima firmi, Fakulteta Tehničkih Nauka u Novom Sadu, i Departmana za proizvodno mašinstvo.

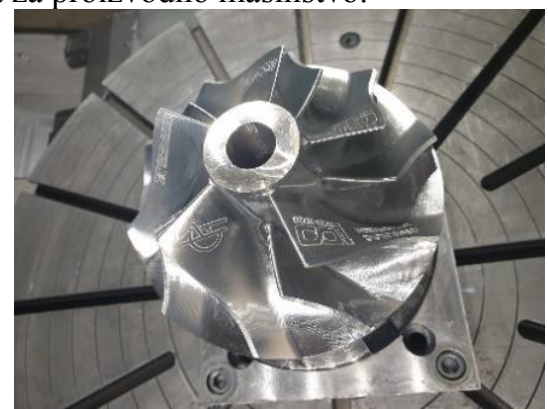

5.3. Slika Gotov komad u realnosti

5.1. Tabela Rezultati merenja na koordinatnoj mernoj mašini

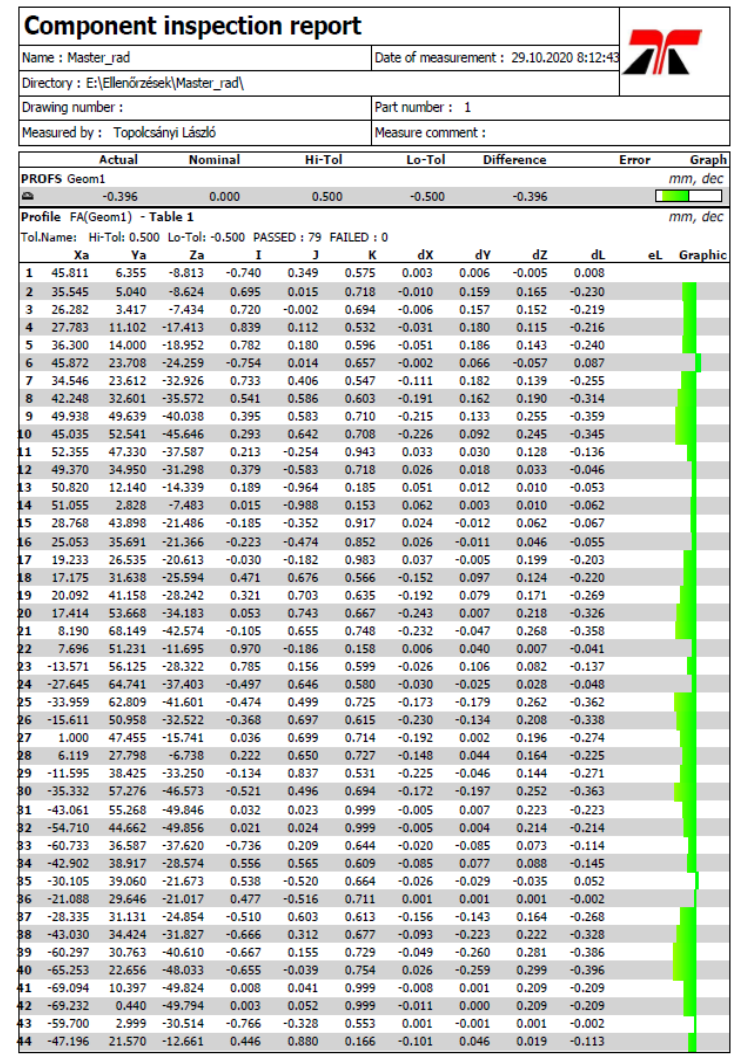

\section{ZAKLJUČAK}

Izrada lopatice turbine je jedan od tehnoloških procesa kod kojih se proizvodnja u serijskom obimu isplati primenom različitih postupaka livenja, zavarivanja itd. Kad je u pitanju završna obrada kao i kompletna obrada kod pojedinične ili maloserijske proizvodnje najekonomičnija je izrada postupkom skidanja strugotine. Za ovakvu obradu se najčešće koriste mašine alatke prilagođene za takve obrade. Nakon istraživanja i analize površina zaključio sam da se sve zahtevane površine mogu obraditi na mašini alatki za petosno glodanje.

Izazov koji je zadatak rada postavio je bio napraviti lopaticu turbine na višenamenskoj petosnoj mašini alatki uz optimalne rezultate. Za primenu ovakve obrade je $u$ okruženju (pa čak i u državi) tehnički i kadrovski sposobno samo nekoliko kompanija. Zbog toga su za izbor alata i strategije obrade korišćeni literaturni izvori (preporuke proizvođača, naučni radovi i stručni tekstovi).

Kao što je u predhodnom tekstu već naglašeno ekonomičnost izrade proizvoda direktno zavisi od vremena izrade radnog predmeta na petosnoj mašini alatki. Zbog toga je bitno optimizovati zahvate obrade, što u ovom slučaju nije urađeno zbog nedostatka iskustva kod izrade toliko složenih delova.

Sledeći korak u unapređenju tehnologije obrade bi bila optimizacija procesa i povećanje ekonomičnosti izrade proizvoda.

\section{LITERATURA}

[1] Devedžić, G. : CAD/CAM tehnologije, Mašinski fakultet u Kragujevcu, 2009.

[2] Tabaković, S.: Osnove računarom integrisane proizvodnje i karakteristični modeli CIM sistema, Fakultet Tehničkih Nauka, Novi Sad, 2012

[3] Öttengelyes megmunkálások I. - alapfogalmak URL:https://www.cnc.hu/2013/09/ottengelyesmegmunkalasok-i-alapfogalmak/

[4] Öttengelyes megmunkálások II. $\quad-\quad 3+2$ tengelyes megmunkálások programozása

URL:https://www.cnc.hu/2013/09/ottengelyesmegmunkalasok-ii-32-tengelyes-megmunkalasokprogramozasa/

[5] Öttengelyes megmunkálások III. - szimultán 5 tengelyes megmunkálás:

URL:https://www.cnc.hu/2013/10/ottengelyesmegmunkalasok-szimultan-5-tengelyes-megmunkalas/

\section{Kratka biografija:}

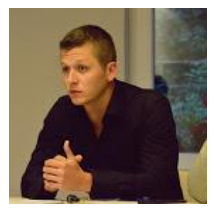

Mate Kerepesi rođen je u Kikindi 1992. god. Master rad na Fakultetu tehničkih nauka iz oblasti Proizvodno mašinstvo -odbranio je 2021.god.

\section{kontakt: kerepesi.mate007@gmail.com}

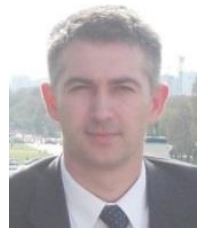

Slobodan Tabaković rođen je u 1974. god. Doktorirao je na Fakultetu tehničkih nauka 2008. god., a od 2018 je zvanju redovni profesor. Oblast interesovanja su Mašine alatke, Fleksibilni tehnološki sistemi i automatizacija postupaka projektovanja. 